\title{
La haine du théâtre. Controverses européennes sur le spectacle. Vol. 2: Discours et arguments, dir. F. LECERCLE et $\mathrm{C}$. THOURET
}

\section{Laura Rescia}

\section{OpenEdition}

\section{Journals}

\section{Edizione digitale}

URL: https://journals.openedition.org/studifrancesi/31628

DOI: 10.4000/studifrancesi.31628

ISSN: 2427-5856

\section{Editore}

Rosenberg \& Sellier

\section{Edizione cartacea}

Data di pubblicazione: 1 août 2020

Paginazione: 397-398

ISSN: 0039-2944

\section{Notizia bibliografica digitale}

Laura Rescia, «La haine du théâtre. Controverses européennes sur le spectacle. Vol. 2: Discours et arguments, dir. F. LECERCLE et C. THOURET», Studi Francesi [Online], 191 (LXIV | II) | 2020, online dal 01 septembre 2020, consultato il 18 septembre 2021. URL: http://journals.openedition.org/studifrancesi/ 31628 ; DOI: https://doi.org/10.4000/studifrancesi.31628

Questo documento è stato generato automaticamente il 18 septembre 2021.

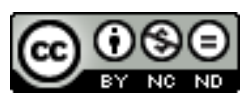

Studi Francesi è distribuita con Licenza Creative Commons Attribuzione - Non commerciale - Non opere derivate 4.0 Internazionale. 


\title{
La haine du théâtre. Controverses européennes sur le spectacle. Vol. 2: Discours et arguments, dir. F. LECERCLE et C. THOURET
}

\author{
Laura Rescia
}

\section{NOTIZIA}

La haine du théâtre. Controverses européennes sur le spectacle. Vol. 2: Discours et arguments, dir. F. LECERCLE et C. THOURET, Toulouse, Presses universitaires du Midi, 2019, "Littératures classiques" 99, 194 pp.

1 Il secondo numero che la rivista "Littératures Classiques" dedica alle querelles europee sulla pericolosità dello spettacolo riunisce quattordici articoli, che completano un'indagine approfondita e ricca di spunti interpretativi, grazie anche alla dimensione comparata.

2 La prima sezione, intitolata «Le théâtre, lieu démoniaque et art trompeur» si concentra sulla condanna del teatro da parte dei Padri della Chiesa. L'argomento dell'idolatria, sviluppato da Tertulliano e riformulato nella Patristica, è l'oggetto dell'articolo di MARIE-HÉLÈNE GOURSOLAS, La notion d'idolâtrie dans la polémique contre le théâtre en France et en Angleterre aux XVI et XVII siècles: enjeux d'un argument récurrent, pp. 13-24. Dietro a un utilizzo apparentemente uniforme dello stesso argomento in epoca moderna, si svelano tre diversi obiettivi: l'evocazione patristica, con conseguente condanna dell'essenza stessa del teatro; l'utilizzo antipapista, e infine l'uso metaforico, che trasforma drammaturghi e attori in idoli fascinosi che distolgono il cristiano dalla sua dottrina. ENRICA ZANIN, La vraisemblance: un argument contre le théâtre?, pp. 25-37, analizza specificamente gli attacchi contro il teatro in Francia, Italia e Spagna nel secondo Seicento, che poggiano sulla critica della mimesi, per poi valutare in qual misura essa 
ha contribuito al consolidarsi della teoria della verosimiglianza. MARIE SAINT-MARTIN, Haine du théâtre et démonologie: de la possession démoniaque à la catharsis, pp. 39-50, dimostra una certa porosità tra $\mathrm{i}$ trattati di demonologia e quelli dei detrattori del teatro, attingendo entrambi agli argomenti dei Padri della Chiesa, e a Sant'Agostino in modo particolare: i concetti di possessione, illusione, empatia, incarnazione si trasferiscono e si riverberano da un dominio discorsivo all'altro. Ed è ancora il pensiero agostiniano, nei suoi prolungamenti nelle controversie spagnole secentesche, al centro dell'intervento di FLORENCE D'ARTOIS, "Y Agustino, capitán de todo»? Paradoxes de l'augustinisme dans les controverses sur le théâtre en Espagne, pp. 51-62. Il pensiero di Agostino viene dapprima utilizzato implicitamente, ed è in prevalenza alla Città di Dio che si guarda; alla fine del secolo, invece, il riferimento si fa più esplicito, ma evitando il dibattito ontologico, e focalizzandosi sull'interdizione delle rappresentazioni teatrali.

3 La seconda sezione, «Le spectacle ou le règne du sensible», raggruppa gli interventi relativi all'argomentario sul corpo degli attori/attrici e degli spettatori/spettatrici, presente negli scritti polemici antiteatrali.

FRANÇOISE DECROISETTE, La peur du corps dans les textes sur le théâtre des zanni aux XVI et XVII siècles, pp. 63-78, mette in luce come la fobia del corpo si amplifichi in parallelo alla progressiva professionalizzazione del teatro: in Italia, come noto, la Commedia dell'Arte sviluppa un'eloquenza corporea che suscita reazioni opposte, e talvolta ambigue, di attrazione e ripugnanza. Per rispondere alle critiche mosse dai censori del teatro, gli attori sviluppano un discorso di legittimazione del loro sapere e della loro intelligenza, dal quale appare comunque evidente che questi sono indissociabili dalla corporeità.

5 Il discorso scandalizzato dei detrattori dello spettacolo diviene implacabile nei confronti delle donne, a cui sono dedicati tre articoli. ANDREA FABIANO, Haine du théâtre, haine des femmes: fascination et censure dans la réflexion théorique et dans la pratique théâtrale italiennes au XVIII ${ }^{\mathrm{e}}$ siècle, pp. 79-91, focalizza la sua riflessione sul modo in cui il corpo femminile diviene «tramite di quella pulsione scopica, fondativa del rapporto tra la scena e la sala». I discorsi degli oppositori più rigorosi come quelli dei riformatori moderati (Maffei e Riccoboni), lo pongono al centro del loro interesse. Goldoni, dovendo destreggiarsi tra esigenza di moralizzazione e necessità di efficacia teatrale, mette in scena un discorso meteatrale ne La cameriera brillante e ne La locandiera, in cui la riflessione sul fascino del teatro e delle attrici diviene drammaturgia.

6 Anche il problema del pubblico femminile, che con l'avanzare della modernità si accresce progressivamente, occupa un posto d'onore nel discorso antiteatrale. VÉRONIQUE LOCHERT, «Regarder hardiment et avec plaisir» ou «détourner les yeux»? Les dangers du théâtre pour les spectatrices (France-Angleterre, $\mathrm{XVI}^{\mathrm{e}}$-XVII e siècles), pp. 93-105, ne esamina lo sviluppo in Francia e Inghilterra tra Cinque e Seicento. Il teatro è descritto come particolarmente pericoloso per le donne, sia in relazione a quanto avviene sulla scena che a quanto succede tra il pubblico: la seduzione dei sensi è il rischio e l'effetto dello spettacolo, intrinsecamente corruttore dei costumi. SARAH NANCY, De la condamnation de la mixité à la crainte de l'altération. Où sont les femmes dans la haine du théâtre?, pp. 107-119, dimostra come la denuncia degli effetti negativi dello spettacolo teatrale sulle donne non si riduca alla semplice condanna della presenza effettiva di queste negli spazi teatrali - palcoscenico o parterre. È possibile infatti individuare dei procedimenti di stigmatizzazione metaforica, di femminizzazione di quanto è deprecabile nel teatro: seduzione e fascinazione. Sullo spettacolo teatrale si riverbera dunque il pericolo del 
femminino. La sezione prosegue con l'articolo di SYLVIANE LÉONI, Fiction et fonction du regard dans le discours anti-théâtral, pp. 121-129, che analizza come, con l'avvento del paradigma scientifico che seguì alle scoperte di Keplero e al pensiero di Descartes, anche lo sguardo venga considerato diversamente rispetto al periodo precedente. L'idea di compenetrazione tra soggetto e oggetto viene rifiutata come mera superstizione: di conseguenza, anche il discorso sulla visione teatrale cambia. Non è più l'oggetto in sé a costituire pericolo, quanto la fragilità morale dello spettatore, che si lascia piegare allo spettacolo delle passioni. MARION LAFOUGE, Avatars et métamorphoses d'une nouvelle querelle coloriste. Le paradigme pictural dans les discours et débats sur l'opéra, pp. 131-142, rintraccia in tre querelles - quella di Alceste (1674), quella sulla musica francese e italiana (1705) e quella dei Bouffons (1753) - un paradigma colorista, che si piega a un utilizzo ideologico del valore del colore.

7 La terza sezione, «Anthropologie du spectateur», interamente dedicata al rapporto tra la scena e la sala, prende avvio con l'articolo dell'anglista ELLEN MACKAY, La figure $d u$ public dans l'imaginaire théâtrophobe anglais de la première modernité, pp. 143-152, che si concentra sul discorso del personaggio di Wengrave ne The Roaring Girl (1611) di Middleton e Dekker: l'immagine del parterre come "isola galleggiante", sulla quale lo spettacolo dovrà navigare, deriva dalla concezione di un pubblico passivo, nel quale si realizza un blocco del pensiero: gli spettatori diventano una sorta di collettività indifferenziata, un'anticipazione del concetto di massa acritica. Si torna a volgere lo sguardo all'Italia secentesca con BRUNA FILIPPI, La tolérance comme masque de la haine du théâtre (Italie, XVII siècle), pp. 153-163, che si focalizza sulla nozione di tolleranza sviluppata nel noto trattato del gesuita Ottonelli Della christiana moderazione del theatro (1646-1652), in cui, dietro al principio di comprensione tollerante, si cela una forte ostilità contro i dispositivi percettivi del teatro, da cui conseguono suggerimenti di forme di restrizione mentale, necessarie ad ottenere la salvezza dell'anima. L'articolo di LOGAN J. CONNORS, "Sur la superficie de notre coeur»: de la condamnation du théâtre à une science théâtrale de l'homme (1694-1719), pp. 165-175, prende avvio dalle analisi sull' esperienza dello spettatore, presenti in numerosi discorsi contro il teatro. Passa in seguito alla disamina del pensiero di Jean-Baptiste Dubois (1670-1742), relativo al funzionamento delle emozioni teatrali, per poi tentare di connettere tale questione con l'utilizzo strategico, sociale e politico, delle emozioni. L'ultimo intervento, LARRY NORMAN, La théâtrophobie et la «nouvelle philosophie» moderne: le cas de Jean Terrasson, pp. 177-187, è dedicato a un Moderno che prese parte alla seconda fase della celebre querelle, nella quale si scagliò violentemente non solo contro il teatro classico, bensì anche contro quello coevo. Nelle sue invettive, da lui definite filosofiche, si ritrovano diversi argomenti teologici tradizionali; questa considerazione consente di inserire tale figura di critico e diplomatico nell'evoluzione del discorso sul teatro, da Perrault a Rousseau, dove appare inopportuno separare l'approccio religioso da quello profano. 